\title{
Can minimalism about truth embrace polysemy?
}

\author{
Katarzyna Kijania-Placek ${ }^{1}$
}

Received: 10 January 2016 / Accepted: 16 September 2016 / Published online: 8 October 2016 (C) The Author(s) 2016. This article is published with open access at Springerlink.com

\begin{abstract}
Paul Horwich is aware of the fact that his theory as stated in his works is directly applicable only to a language in which a word, understood as a syntactic type, is connected with exactly one literal meaning. Yet he claims that the theory is expandable to include homonymy and indexicality and thus may be considered as applicable to natural language. My concern in this paper is with yet another kind of ambiguity-systematic polysemy - that assigns multiple meanings to one linguistic type. I want to combine the characteristics of systematic polysemy with the Kaplanian insight that meanings of expressions may be defined by semantic rules which assign content in context and to ask the question if minimalism about truth and meaning is compatible with such rule-based systematic polysemy. I will first explain why the expressions that exhibit rule-based systematic polysemy are difficult to combine with a truth theory that is based on a use theory of meaning before proceeding to argue that indexicals and proper names are such expressions.
\end{abstract}

Keywords Minimal theory of truth · Use theory of meaning · Polysemy · Proper names $\cdot$ Indexicals

\section{Minimalist theories of truth and meaning}

In "Truth" Paul Horwich declares that

the explanatorily basic fact about our use of the truth predicate is our tendency to infer instances of 'The proposition that $p$ is true' from corresponding instances of

Katarzyna Kijania-Placek

katarzyna.kijania-placek@uj.edu.pl

1 Institute of Philosophy, Jagiellonian University in Krakow, 52 Grodzka St., 31-044 Kraków, Poland 
' $p$ ', and vice versa, whenever (a) each ' $p$ ' is replaced with tokens of an English sentence, ${ }^{1}$ (b) these tokens are given the same interpretation as one another, (c) under that interpretation they express the content of a statement (a proposition), and (d) the terms 'that' and 'proposition' are given their English meanings. (1990/1998, p. 126)

My paper will mainly be concerned with condition (b) and the word "interpretation" that occurs in it. According to Horwich, truth is based on the concepts of meaning and proposition which are conceptually prior to it (1990/1998, p. 129,2010 b, p. 17). As a result, the sameness of interpretation may be explained with the help of the identity of propositional constituents or sameness of meaning but, on pain of circularity, cannot rely on the sameness of truth conditions. Since the identity of propositions is defined as sameness of meaning (1990/1998, p. 134), meaning emerges as the fundamental notion for the proper understanding of condition (b). The minimalist theory of meaning endorsed by Horwich is the use theory of meaning (UTM) and he claims that his "minimalist thesis is the product of two prior claims: first, that our underived endorsement of the equivalence schema is explanatorily fundamental with respect to the overall use of the truth predicate; and second, that the meaning of any word is engendered by the fact about it that explains its overall use." (2001, p. 150)

The axioms of the theory of truth are propositions such as:

$<<$ Snow is white $>$ is true iff snow is white $>$,

and in general, all the propositions whose structure is $\left(1990 / 1998\right.$, p. 17): ${ }^{2}$

$\left(\mathrm{E}^{*}\right)<<\mathrm{p}>$ is true iff $\mathrm{p}>$.

However if 'p' were to be replaced by an arbitrary English sentence, not all instances of $\left(\mathrm{E}^{*}\right)$ would be true, something that Horwich is the first to admit. When we consider indexicality or homonymy, for example, for an equivalence that contains the word "bank" to be reliable we must ascertain that it is interpreted in the same way on both sides of the equivalence sign, as "there are two different types (with the same shape but different meanings) that it can designate" (1990/1998, p. 100). One way of explaining what the same interpretation amounts to would be to demand that the word has the same propositional contribution defined by the same truth-conditional contribution. But, as mentioned above, this way is blocked for Horwich as it would make the theory of truth circular. Instead, Horwich defines meaning according to a use theory of meaning that bases the meaning of a word on non-semantic facts about its use: ${ }^{3}$

The meaning of a word, w, is engendered by the non-semantic feature of $w$ that explains w's overall deployment. And this will be an acceptance-property of

\footnotetext{
1 In other places the equivalence schema is restricted to declarative sentences (see Horwich 1990/1998, p. 4) and, I assume, that is how is should be understood.

2 Horwich writes ' $<\mathrm{p}>$ ' for 'the proposition that p' (1990/1998, p. 10, 2010a, p. 5).

3 Compare also Horwich (1990/1998, pp. 70-71, 126n), (2001, p. 162) or (2005, p. 26).
} 
the following form:- 'that such-and such w-sentences are regularly accepted in such-and-such circumstances' is the idealised law governing w's use [...] (by the relevant 'experts', given certain meanings attached to various other words). ${ }^{4}$ (2005, p. 28)

By "non-semantic" Horwich does not mean "physical", but intends to preclude an account of meaning based on concepts such as "reference", "belief" or, obviously, "truth" or in general "anything that would itself require analysis in terms of meaning" (2005, p. 37). He additionally demands that the overall use of a word be "explained by a certain core use, by the acceptance of a certain narrow set of sentences containing it" (2005, p. 42) and that the basic uses of words "have consequences for the usage of all the complexes into which they enter." (2005, p. 218) That prominently includes inference schemes containing a given word, as well as translatability or preservation of acceptance under substitution of terms with the same meaning. 5

Although Horwich's theory is primarily designed to deal with "unambiguous word types - with sounds [...] that possess a single literal semantic meaning", he thinks that it is "easily broadened" to include ambiguity: "A word type's having more than one meaning will consist in the need for more than one non-semantic ground, i.e. more than one basic acceptance property, in the explanations of when and why tokens of that type occur. And the meaning of an individual token is fixed by the particular basic acceptance property to which its occurrence is linked." (2005, p. 29) That sounds plausible for words like "bank", as the following schema is invalid exactly due to the equivocation of the word "bank":

(1) Tom put his money into a bank. / So, his money is deposited by a river.

Although the invalidity of one schema is not sufficient to show that the non-semantic grounds - the patterns of use of "bank 1 " (financial institution) and "bank 2 " (embankment $)^{6}$ - are not interconnected, I will assume for the sake of argument that this can be established and will grant Horwich's claim that he can account for this kind of ambiguity that is exemplified by "bank", i.e. for homonymy. In the next section I will turn to a different kind of ambiguity — polysemy — which is partly defined by the acceptability of inference patterns across different types of use of one word. But before that, I will turn to Horwich's treatment of indexicality.

\footnotetext{
4 Horwich admits that for some words "the group of 'experts' will more-or-less coincide with the whole community”. (2005, pp. 52-53) Indexicals and proper names, on which my arguments are based, arguably belong to this category and that is why in what follows I will ignore the reference to experts.

5 "[T]he property of a word that accounts $[\ldots]$ for its overall usage is what constitutes its meaning [...] [I]t accounts for a range of prominent facts about meaning, namely,

(1) the role of attributions of meaning in the explanation of sentence-acceptance, inference, and nonlinguistic behaviour;

(2) the epistemological import of these phenomena for the confirmation of attributions of meaning;

(3) the fact that acceptance is preserved under inter-substitution of terms with the same meaning;

(4) the utility of translation manuals, i.e. of knowing the meanings of another person's words." (Horwich 2005, pp. 39-40)

6 I ignore other meanings of "bank".
} 


\subsection{Horwich's treatment of indexicals}

What is meant by "interpretation" becomes especially important when we turn to indexicals and demonstratives, as it is their defining characteristics that two tokens of the same sentence that contains an indexical expression may express different propositions. Since UTM is concerned with expression types "individuated non-semantically, e.g. in terms of their sounds or shapes" (2005, p. 28), ${ }^{7}$ Horwich claims that his theory gives a meaning in the sense "in which "I" has a single meaning in English, the same one that "Ich" has in German". (2005, p. 28) The problem is, however, that this kind of meaning is insufficient for the expression of propositions. He is thus prepared to "deny that meaning determines reference" and to claim that "the referent of a term is fixed in part by the context in which it occurs." (2001, p. 154). Furthermore we are told that:

If $x$ is context-sensitive-if it is an indexical or a demonstrative- then " $e$ " is constrained by a batch of rules, including

$x$ means $I \rightarrow[x$ expresses $\langle e\rangle(d r) \leftrightarrow e=$ the speaker of the utterance]

$x$ means NOW $\rightarrow[x$ expresses $\langle e\rangle(d r) \leftrightarrow e=$ the time of the utterance $]$

$x$ means THAT $F \rightarrow[x$ expresses $\langle e\rangle(d r) \leftrightarrow e=$ the $\mathrm{F}$ to which the

speaker is attending] (1998, p. 84)

where " $\langle e\rangle(d r)$ " is the propositional constituent of the expression " $\mathrm{e}$ " interpreted de re. Because there are no speakers or utterances when we consider just expression types, for sentences containing indexicals the equivalence schema-since it concerns propositions (1990/1998, p. 16) — makes sense only for utterances in context and additionally: "an instance of the disquotational schema holds if it is asserted in a context that is not relevantly different from the context of the utterance whose truth is in question." (1990/1998, p. 99) We thus need "a restricted form of the disquotational principleone in which the way that ' $p$ ' is construed when it is mentioned on the left-hand side is the same as the way it is construed when it is used on the right-hand side." (1990/1998, p. 99) Yet for indexicals the relevant similarity of context intuitively amounts to the identity of the referent, so it turns out, as Horwich admits, that for indexicals we need to "pick out an expression-type on the basis, not only of syntactic form (i.e. physical character), but also on the basis of meaning (or, more specifically, the propositional constituent expressed)." (1990/1998, p. 100, also p. 133) Horwich's declaration from "Meaning" confirms the intuitive claim; he states there that a de re propositional constituent is "simply the referent of the term used to articulate it" (1990/1998, p. 85). Thus the sameness of interpretation in the case of indexicals and demonstratives used deictically amounts precisely to the sameness of the referent, which is at odds with Horwich's other claims that a minimal account of meaning should be based on non-semantic concepts and that "it is a mistake to explain truth in terms of reference" (1990/1998, p. 8). I will not dwell on this matter here, however, and will simply take Horwich's word for it that a deflationary theory of reference is possible $\left(1990 / 1998\right.$, p. 10). ${ }^{8}$

\footnotetext{
7 Compare also Horwich (1990/1998, p. 123).

8 But compare Gibbard (2008, p. 165) for a dissenting opinion.
} 
In what follows I will thus assume that the minimal theory of truth can account for the deictic uses of indexicals. My worry will be about the non-deictic uses of those expressions.

Although proper names are not indexicals in the sense that the exact character of their contextual dependence is not given by their linguistic meaning, ${ }^{9}$ they share many semantic features with indexicals. When used referentially they are arguably rigid designators (compare Kripke 1972), they are not shiftable by operators in the language and they do not refer out of context, i.e. when considered as expression types. ${ }^{10}$ The name type "Paul" can be used to refer to many different people or even objects and refers only when uttered. As it was the case with indexicals, the reference is fixed "by the context in which it occurs." (Horwich 2001, p. 154) In analogy with indexicals, the equivalence schema for sentences containing proper names must thus be relativized to context and based on the idea of "the same propositional constituent" or "the same interpretation". In the following sections I will mainly be concerned with the question of the extent to which different types of propositional constituents that are required by the actual usage of proper names can be accounted for by Horwich's use theory of meaning and thus with the adequacy of his theory of truth which is based on the theory of meaning as a theory of the concept of truth for natural language. Especially, I will be concerned with the question to what extent the mechanism of meaning attribution proposed by Horwich's UTM can deliver separate meanings for different kinds of uses of proper names and indexicals - including their non-referential uses - that are suitable as propositional constituents figuring in the instances of the equivalence schema. But before that, in the following subsection I will consider a potential objection to the relevance of any considerations that rely on ambiguity to the questions of truth. ${ }^{11}$

\subsection{Sentences versus propositions}

Ambiguity, be it homonymy or polysemy, as well as indexicality, are properties of linguistic items, while "truth does not apply to sentences but to what is said by their uses, i.e. to propositions". Even though Horwich sometimes writes as if truth applied

\footnotetext{
9 The validity of this claim is sustained even if it is assumed that proper names have no linguistic meaning.

10 Actual proper names differ in this respect as some are in fact used to refer to just one object ("The Thirty Years' War") and thus in a sense refer out of context. My thanks go to an anonymous referee for making me be more precise here. But even such names depend on the context of use for their referent, which is delivered by the social convention operative for this name in that context. It just so happens that the same convention is operative in all contexts (or, arguably, there are contexts of use, in which no social convention for that name is operative). Additionally, the difference is only factual and nothing in the rules of deploying the name prevents us from starting a new communication practice to call a different war by that name. In this respect, proper names are different from other words: if we decided to call white things "red" we would be changing the language and the change would only take effect if accepted by other members of the group. As with indexicals such as "he" we are free to use them in the same language to refer to any man we wish, providing our intention is communicable in a context of use, with proper names it is permissible to reuse the same name for another person or object without a change of language. There is no analogous permissibility for predicates or common nouns.

11 This objection has in fact been stated by an anonymous referee.
} 
to sentences, in other places he is clear that "the truth predicate applies to propositions" (Horwich 2010b, pp. 27, 32) and he even takes it as an indispensable principle of his theory that "only propositions are true" (Horwich 2001, p. 164; 2010c, p. 43). Sentences should thus be considered as truth-evaluable only as far as they express propositions. But since propositions themselves, or propositional constituents, cannot be properly speaking ambiguous, considerations of polysemy do not seem to be relevant to the questions of truth and arguments based on polysemy cannot challenge Horwich's theory of truth.

This objection is well founded and requires careful consideration. When Horwich talks about sentences being true he always has in mind meaningful sentences that are true or false only indirectly, by virtue of expressing true or false propositions, and not sentences of a formal theory. In this respect he perhaps inadvertently follows Tarski (1933, 1958), whose work on truth always concerned meaningful sentences of a formalized language rather than sentences of a formal language as such. The important difference is that sentences of a formal language are syntactic objects for which the question of truth does not arise, ${ }^{12}$ while the meaningful sentences of a formalized language are indirectly truth or false-depending on the truth-value of their content. Horwich is not interested in formalized languages but retains the practice of talking about sentences being true when what he really means is that the content expressed by that sentence is true. This is clear when he applies truth directly to sentences, but by first relativizing the sentences to the particular meanings that they express:

the truth condition of a sentence is linked to its meaning via the explanatorily fundamental schema

$\mathrm{s}$ means that $\mathrm{p} \rightarrow(\mathrm{s}$ is true $\leftrightarrow \mathrm{p})$

or perhaps

$\mathrm{s}$ means that $\mathrm{p} \rightarrow(\mathrm{w})$ (s is true in $\mathrm{w} \leftrightarrow \mathrm{p}$ in $\mathrm{w}$ ) (Horwich 2008a, p. 321)

Having said all this, however, we should be careful not to interpret the letter "p" in the equivalence schema as standing for propositions or as a propositional variable. ${ }^{13}$ First of all, Horwich is clear that the equivalence sign should be interpreted as a material biconditional (Horwich 2010c, p. 36) and propositions, being abstract objects, strictly speaking cannot flank a material biconditional. Furthermore, if "p" itself were a proposition, both the convention of using ' $<\mathrm{p}>$ ' for 'the proposition that p' (1990/1998, p. 10, 2010a, p. 5) and the phrase 'the proposition that p' itself would make no sense. As Horwich insists, "the terms 'that' and 'proposition' are given their English meanings" (1990/1998, p. 126) and that-clauses in English require supplementation by a sentence-like syntactic objects, which express propositions but are not themselves propositions. What denotes a proposition is the whole phrase "that p" of which " $p$ " is a propositional vehicle. It is thus impossible to express the equivalence schema without symbols standing for propositional vehicles. It follows that the " $p$ " in the equivalence schema is to be replaced by a propositional vehicle, be it a sentence

\footnotetext{
12 This question arises only for sentences of a formal language interpreted in a model (or by an alternative semantic mechanism.)

13 This way of understanding the letter "p" in the equivalence schema has been suggested by an anonymous referee.
} 
or any other vehicle, ${ }^{14}$ and such a vehicle is susceptible to ambiguity. Yet, according to Horwich, for the equivalence schemes to be acceptable, ambiguous vehicles must possess meanings that are separable and of which only one meaning is activated in each equivalence instance. Thus the question I am going to ask is if the use-theory of meaning that is proposed by Horwich is able to deliver word-meanings that would be in this sense suitable as propositional constituents for the instances of the equivalence schema.

\subsection{Meaning based on acceptance-properties}

Horwich's critique of what he calls "mainstream formal semantics" (Horwich 2008a, p. 309) is based on his conviction that such a semantics is unable to explain "the non-semantic acceptance-phenomena that a decent empirical semantics surely ought to explain". (Horwich 2008a, p. 316; compare also p. 318) He considers semantics to be a part of linguistics taken as "an empirical science—-standing alongside psychology, neurology, biology, physics, etc.", which "should be testable against concrete observable events" (Horwich 2008a, p. 315; compare also 2008b, p. 234). According to Horwich, we should base semantics on observable facts of acceptance and on actual inference patterns:

As for which such phenomena are of special concern to semantics-rather than to other parts of linguistics, such as phonology, syntax, or pragmatics-I would say that the facts that it is obliged to explain are facts concerning the circumstances in which sentences are accepted. And prominent amongst such acceptance-facts are facts concerning inferential activity - facts to the effect that this sentence tends to be inferred from that one. (Horwich 2008a, p. 315)

However, the above quotation may be misleading with regards the exact nature of Horwich's enterprise as it seems to suggest that he takes sentences to be the primary bearers of meaning, as if he were following Frege's context principle, according to which "it is only in a context of a sentence that a word has meaning" (Frege 1884, p. 60). But Horwich is far from agreeing with Frege on this point and he explicitly proposes "[a]n alternative approach-involving a sort of explanatory inversion of the standard one" (Horwich 2008a, p. 314). According to his proposal we must first identify "the theoretical-meanings of words, and then, presupposing compositionality, [...] trivially deduce the theoretical meanings of sentences." (Horwich 2008a, p. 314; compare also 2010d, p. 140) This does not contradict his thesis that the meanings should be discovered by observations of sentence acceptance patterns, as Horwich claims that "the idea is to suppose (a) that certain facts concerning sentence usage, rather than sentence meanings, are what constrain the problems of giving theoretical characterizations of the meanings of words [...]; and (b) that once these problem has been solved, we will—in light of compositionality—be able to arrive [...] at the meanings of sentences." (Horwich 2008a, p. 314; compare also p. 321) Horwich thus

14 For an unequivocal claim that "p" is to be replaced by a sentence see for example Horwich (2010b, p. 32). 
proposes quite a different picture of semantics from what we are accustomed to after Frege's dictum:

Semantics would then somewhat resemble fundamental particle physics. There, we try to find the basic laws governing electrons, the basic laws governing protons, etc.- - subject to the condition that they will jointly (and together with other general principles) explain the behavior of all the complex objects formed by sticking these entities together in various arrangements. Similarly, according to the picture of semantics that I am proposing, the semanticist of a given language ought to be looking, concerning each word, for the basic law governing its use-subject to the conditions that taken together (and in conjunction with further relevant facts) we can explain the behavior of all the sentences formed by sticking those words together in a variety of arrangements. (Horwich 2008a, pp. 318-319; compare also 2005, p. 218)

The basic units to be explained by a theory of meaning are thus word meanings and sentence meanings, i.e. propositions, are supposed to trivially follow from compositionality (Horwich 1990/1998, pp. 70-71; 2008a, p. 321). According to Horwich, if " $u$ and $v$ express the same proposition", then " $u$ and $v$ have the same use-theoretic construction property” (Horwich 1990/1998, p. 134) and in general:

we can identify the meaning-constituting property of a compositional sentence with its 'construction property'-i.e. with a property of the form

_ is the result of imposing combinatorial procedure, $\mathrm{P}$, on words whose meanings are $<\mathrm{M} 1, \mathrm{M} 2, \ldots, \mathrm{Mj}>$

So, for example, the meaning-constituting property of the Italian "Gira Marte" is its property of being the result of applying a word meaning ROTATES to a word meaning MARS. This property is also possessed by the English "Mars rotates", the German "Mars rotiert", etc.- - which is why all these sentences have the same meaning. (Horwich 2008a, p. 314) ${ }^{15}$

The important meanings - with respect to the suitability of meanings delivered by the UTM for fulfilling the role of propositional constituents required in the equivalence schemes - are thus word meanings. ${ }^{16}$ The identity of propositions is a derived matter according to Horwich's account and cannot be relied upon to ascertain that words, as used in a context, have the same meaning (Horwich 2008a, p. 321). That is why I will concentrate on Horwich's construal of word meanings in the reminder of this paper and on its empirical adequacy against the words of natural language.

He claims that "the main symptoms of a word's meaning are its various ways of being used-i.e. the various facts concerning the sentences containing it that are accepted and the circumstances in which this is done. So the meaning-constituting property will be one that explains all such acceptance phenomena; it will be the word's

\footnotetext{
15 This account of meaning equivalence for propositions does not explain how sentences in languages with a different structure can express the same proposition (compare Gibbard 2008, especially pp. 145-146), but I will leave this issue aside as it does not affect my main argument against Horwich'a proposal.

16 Compare also Gibbard (2008, pp. 141-142).
} 
basic rule of use" (Horwich 2010d, p. 129). ${ }^{17}$ As I have stated at the beginning of this section, these meaning-constituting properties-or "basic acceptance properties" (Horwich 2005, pp. 29, 218) - are supposed to be explanatorily basic in the sense that all other uses of a certain word must be linked to them, i.e. "the basic uses of words must have consequences for the usage of all the complexes into which they enter." (2005, p. 218; compare also p. 29 and 2008a, pp. 233, 235).

Amongst the uses of words that testify to the adequacy of the theory are inference schemes into which words enter as parts of sentences (Horwich 2008a, p. 319). Even though Horwich distances himself from explaining the validity of inferences, since that would require reference to truth, he insists on the requirement that "what needs to be explained [...], is [...] that certain inferences are made (or would be made)" (Horwich 2008a, p. 319). Yet, it is a requirement of a correct inference that a word is used with the same meaning in the premises and in the conclusion. It follows that systematic inference patterns testify on Horwich's account for one meaning of a word that figures in such inferences, i.e. for including in the meaning of a word all aspects that are required for the inference. Homonymous words, like "bank", would exhibit a separate inference pattern for "bank 1 " (financial institution) and "bank 2 " (embankment), which would form the basis for separate non-semantic grounds-acceptance phenomenafor these two word types.

The main thesis of this paper is that the actual uses of indexicals and of proper names are variously interdependent and, in the case of proper names, combined by inference patterns in such a way that precludes postulating separate non-semantic grounds for the respective kinds of uses of those expressions. I shall try to substantiate this claim in the reminder of the paper. If we assume that it is true, it follows that the meaning of a proper name that is delivered by Horwich's type UTM must comprise different kinds of uses of that name considered thus not as several types but as one semantic type. Such meanings are more akin to Kaplanian characters than to truth-evaluable propositional constituents although it is important not to take the analogy too far. The important difference between indexicality and polysemy is that it is a requirement for deicticly used indexicals in inferences that they are used with the same content in the premises and in the conclusion. For an inference from "He is 25 " to "He is an adult" to be correct, both tokens of "he" must not just have the same linguistic meaning, but must refer to the same thing, i.e. have the same content. ${ }^{18}$ So utterances of the same indexical

17 Horwich treats acceptance as "the psychological (but non-semantic) relation to a sentence that is manifested in our relying on it as a premise in theoretical and practical inference." (Horwich 2005, pp. 40-41) In (2008c, p. 455) he declares: "I am using the term, 'accept', in a technical sense, for the particular psychological relation between a person and a sentence that correlates with his believing the proposition expressed by the sentence". In this way he hopes to reduce acceptance to a naturalistic properties. I leave it out of consideration in this paper to what extend he succeeds, but reference to propositions in the above quote-which were to be explained by acceptance facts and compositionality—sheds some doubts on this project. Thanks for an anonymous referee for making me clarify this point.

18 An anonymous referee suggested an analogy that according to him undermines my argument: "Nobody discusses that the inference between "Pablo is older than Maria" and "Maria is younger than Pablo" is not valid because it could be the case that "Maria" and "Pablo" in both premises referred to different individuals. Consistent substitution is a presupposition of logical analysis." I do agree that this kind of inferences could form non-semantic basis for individual uses of the same name type, when used for different people. But I do not base my claim of the polysemous character of proper names on the fact that the same name can 
with reference to different people could in principle be separable. ${ }^{19}$ This is not the case for polysemous words, which admit anaphoric relations and inference patterns across different kinds of uses of the same word. Since the arguments presented can be extended to other polysemous expressions, the minimal conclusion of this paperto anticipate-is that Horwich's theory of truth and meaning requires at least a few adjustments in order to account for systematic polysemy.

\section{Homonymy and polysemy as two kinds of ambiguity}

\subsection{The difference between homonymy and polysemy}

Polysemy and homonymy are two kinds of ambiguity. In the case of homonymy we have two (or many) words and two (or many) unrelated meanings that share one word form, which is a kind of accidental multiple encoding (Falkum 2011). A clear example of a homonym is the word "coach" understood either as a bus or as a sports instructor or the two meanings of "bank" mentioned by Horwich and cited above. No inferential or anaphoric relations exist between homonymous words and they rarely co-occur in the same discourse (Gale et al. 1992).

In the case of polysemy, one word has two (or many) related meanings, like the word "newspaper", used both for the physical object and for its publisher or the word "chicken" used for the bird as well as for its meat. The idea is that in "polysemy, the different senses of a single lexical item are seen as being related in some nontrivial way, whereas in homonymy, the multiple encoding is a matter of historical accident." (Falkum 2011, p. 16) The distinction is easy to formulate but notoriously difficult to define operationally (see Taylor 1989/2003; Falkum 2011). Two criteria for distinguishing homonymy from polysemy are usually mentioned, i.e. etymology and speaker intuitions about the relatedness of words (Lyons 1977) but both of these criteria are unreliable (see Falkum 2011; Koskela and Murphy 2006; Panman 1982).

\footnotetext{
Footnote 18 continued

be used for different people; that feature might be better characterized as an indexicality of proper names. Rather, my claim is based on different kinds of uses of proper names, such as predicative or descriptive uses discussed in Sect. 4. The inference schemes exemplified there-for example (35) or (36)—do not admit consistent substitution, if by that we mean the same propositional constituent. Such examples thus testify against the dictum that "consistent substitution is a presupposition of logical analysis". What is required instead is a systematic relation between aspects of meaning but not identity of propositional contribution.

The same referee suggested that the situation is similar to that of logical inferences "from " $\mathrm{Pa} \& \mathrm{~Pb}$ " to "Pa", in which validity requires consistent substitution of the individual constant". It is indeed a requirement for logical constants but it does not follow just from the fact that they are used in an inference but from their very nature as constants. Logical constants-if interpreted-must be interpreted by the same object, while there is no such requirement for proper names. Horwich insists that he is not interested in proposing a formal semantic theory (in which proper names would typically be interpreted as constants), but in an empirically adequate semantics of natural language. And an actual proper name in a natural language may be and in most cases is used as a referring device for several objects (compare "Aristotle" used in English for the Greek philosopher and for Aristotle Onassis). Proper names are characterized by permissive reference rules and not by exclusive ones (compare Perry 2012). Still, my arguments do not rely on this feature of proper names but on the existence of their non-referential uses.
}

19 Horwich considers such an idea in (1990/1998). Compare note 29 below. 


\subsection{Systematic polysemy}

The kind of polysemy that I want to discuss in this paper is, however, a systematic polysemy, characterized by additional features which distinguish it clearly from cases of homonymy. What all the features have in common is a reliance on underlying interpretive mechanisms that are of a general nature and as such are not specific to individual languages. ${ }^{20}$ Those features include the following:

(a) Systematically polysemous ambiguity is sustained cross-linguistically, i.e. it occurs with the same words in several languages (see Pethö 2001; Leckie 2013). ${ }^{21}$ Both homonymy and non-systematic polysemy are specific to individual languages or historically related groups of languages. Thus:

(2) I ate yak for dinner yesterday.

translates into Polish directly as:

(2a) Jadłam wczoraj jaka na obiad,

while the following dialog makes no sense when translated into Polish:

(3) A: Let's meet at the bank.

B: Which bank do you mean: the river bank near my house or the branch of HSBC on Cornmarket?

as the two senses of "bank" translate into "bank" and "brzeg rzeki" respectively. 22,23

(b) Systematic polysemy is productive and creative

I use the term "systematic polysemy" (following Pethö 2001 and many others), for what Apresjan, who was the first to distinguish this phenomenon, called "regular polysemy" and characterized in the following way:

Polysemy of the word A with the meanings $a_{i}$ and $a_{j}$ is called regular if, in the given language, there exists at least one other word $\mathrm{B}$ with the meanings $b_{i}$ and

\footnotetext{
20 I consider it a substantive task of semantics to provide such underlying mechanisms that would explain, to use Dancy's words (2004, p. 196), all "sorts of semantic contribution that the term can make to a larger context, and to have a general understanding of what sorts of context are those in which it will make this or that sort of contribution". In Sects. 3 and 4 I will propose concrete interpretive mechanisms that in my view are operative in the case of indexicals and proper names respectively and from which the features characteristic for systematic polysemy — as it is characterized in the linguistic literature and listed below-seem to follow.

21 But systematic polysemy will be blocked in a language that contains a separate word for one of the meanings (see Leckie 2013).

22 "A: Spotkajmy się przy banku. B: *O który bank Ci chodzi: brzeg rzeki koło mojego domu czy oddział HSBC na Cornmarket?".

23 The meaning of 'yak' in (2) depends on the count / mass alternation and is predicted in languages that exhibit this distinction. Alternations of this kind are, according to Nunberg, based on the rule of 'grinding', "which turns count nouns into mass nouns that denotes the stuff they are made of, as in 'We ate chicken', 'They wear beaver', or 'The table was made of oak"' (Nunberg 1995, p. 117). The criterial status of this feature should be understood as a postulate of a need of an explanation in case a particular meaning is not available in a language (see note 21 for one such explanation). No such regularity across languages is presupposed for homonymy.
} 
$b_{j}$, which are semantically distinguished from each other in exactly the same way as $a_{i}$ and $a_{j}$ and if $a_{i}$ and $b_{i}, a_{j}$ and $b_{j}$ are non-synonymous (1973, p. 16)

Systematic polysemy is thus based on a relation between meanings that is intralinguistically uniform and that accounts for the fact that users understand and are able to produce novel utterances with polysemous meanings. ${ }^{24}$ This productivity of systematic polysemy excludes an account of this type of ambiguity in terms of sense enumeration (Pustejovsky 1995, p. 42).

(c) If a competent speaker knows one of the polysemous meanings, he/she knows them all.

This feature is a consequence of the productive character of systematic polysemy. A learner of English might make the mistake of using "pig" for "pork" but his mistake will be due to his lack of knowledge of "pork", the existence of which in English blocks the alternation of animals and their meats in this particular case. But he will understand "yak" used for yak's meat as long as he has "yak" in his language repertoire.

(d) Anaphoric relations across systematically polysemous meanings are usually allowed (compare Pethö 2001).

Typical examples attesting to this feature involve the use of "book" with its senses of the material and the abstract object, like in the following example of Chomsky (2000, p. 16):

(4) The book that he is planning will weigh at least five pounds, if he ever writes it.

In (4) 'the book' is used for the material object but the anaphoric relation is to the abstract object (compare Hunter 2010).

(e) Inferential relations across some systematically polysemous meanings obtain.

Inferential relations obtain between those kinds of polysemous meanings which are highly conventionalized, such as those based on the count / mass distinction for nouns:

(5) A: Have you ever eaten yak?

B: Well, we had this little yak in our garden, but last month my mother killed it and made a nice dinner out of it. So, yes, I must admit I have eaten yak.

This inference is based on the following schema:

$\mathrm{X}$ eats a meal made out of a/the/this/that Y. / So, X eats Y.

where $\mathrm{X}$ is a term denoting people and $\mathrm{Y}$ is a term for a kind of animal. The inferential relations testify for the interconnectedness or, as Pusteyovsky put it, permeability of word senses (1995, p. 47). This feature of systematically polysemous words is the most important as far as the prospect of separation by use patterns of different propositional constituents expressed by the relevant words is concerned.

Systematically polysemous words frequently occur within the same discourse (Krovetz 1998) and sometimes two senses are embodied in one use of a word. In (6) (Pustejovsky 1995, p. 48):

24 Compare Pusteyovsky's remarks about adjectives such as "good" or adverbs such as "fast" in (1995), pp. 43-45. 
(6) John crawled through the broken window.

only the window in the sense of a physical object can be broken while one can just crawl through a window in the sense of an aperture.

All of these features of systematically polysemous words put them apart from homonyms in ways which have implications for a use theory of meaning. The senses of a polysemous word are inferentially interrelated and seem to be activated simultaneously in the same contexts. As Pusteyovsky put it: ${ }^{25}$

What distinguishes the senses in a logical polysemy from the contrastive cases we have discussed [homonymy, KKP] is the manner in which the senses are related. The biggest difference is that, while contextual priming and discourse setting helps disambiguate contrastive senses, it seems irrelevant to the issue of determining the sense of a logically polysemous noun. That is, while contrastive senses are contradictory in nature (that is, one sense is available only if every other sense is not available), complementary senses seem to have a much weaker shadowing effect. Both senses of a logically polysemous noun seem relevant for the interpretation of the noun in the context, but one sense seems 'focused' for purposes of a particular context. (1995, p. 32)

The contradictory nature of homonymous words (or homonymous meanings for one syntactic word-type in Horwich's sense) - the fact that in a context of use it is either this or that sense that is operative-makes the prospect of finding separate non-semantic grounds for the two (or more) senses promising. This is the case for the examples discussed by Horwich ("bank") but the non-contradictory nature of systematically and especially logically polysemous words seems to make the patterns of use of the different senses connected with such a word interrelated in ways that preclude the distinguishing of separate non-semantic grounds. These are, remember, a prerequisite for extending Horwich's theory beyond words that "possess a single literal semantic meaning" as well as beyond homonymous words.

The task seems to be even more difficult in the face of the polysemous character of proper names and indexicals, due to the basic and pervasive character of these kinds of expressions. Since they are not discussed in as much depth in the literature ${ }^{26}$ than the other types of systematically polysemous words mentioned above, I will devote the next two sections to the analysis of their polysemous character which combines polysemy with indexicality. I will focus on the interdependence of the respective senses of these words.

\subsection{Rule-based systematic polysemy}

Traditional theories of polysemy attempt to account for the multiplicity of stable senses for one linguistic unit. The sense of a word determines its propositional contribution. Yet the insight that we gain from the works of Kaplan (1989a, b) about the concept of linguistic meaning calls for a generalization of the understanding of the phenomena of

25 Pusteyovsky's claim is about logical polysemy but it extends to some other kinds of systematic polysemy.

26 The polysemous character of proper names is discussed by Leckie (2013). 
polysemous meaning. According to Kaplan, expressions do not necessarily exhibit a meaning that provides content, i.e. propositional contribution, directly, but may instead rely on a rule that for the same word gives (possibly) different contents in different contexts. Combining the ideas of Kaplan with the traditional accounts of polysemy, I will propose an account of the latter that allows for connecting words not just with sets of stable senses, but also with sets of content generating rules.

The proposal of generalizing polysemy to include rule-based systematic polysemy should not be confused with the ideas of Blutner (1995), who proposes addressgeneration rules as an explanation of the systematicity of polysemy. While his rules operate on different words as input, the addresses - the results of applying a rule to a word - are the stable intentions of a word. Thus once an intension is generated for a word, it provides a content that is stable across contexts (e.g. "'dog as a kind of animal', 'dog as an individual animal', 'dog meat"' for the word 'dog'; compare Pethö 2001). Structurally similar ideas are behind Pustejovsky's (1995) pledge for multiple sense generators in his critique of Sense Enumerative Lexicons. The rules proposed by those authors account for the systematicity of the mechanisms underlying polysemy across the lexicon but once applied to a particular word they generate constant senses and thus multiple but concrete contents. The present proposal, by combining such insights with Kaplanian ideas, aims for a two dimensional model of polysemous meanings: one word (lexeme) may have not just several senses which determine several contents but a several rule-based senses that each may determine different contents in different contexts. In the following sections I will argue that two kinds of words-proper names and indexicals - exhibit this kind of rule-based systematically polysemous meaning and thus pose a challenge both to the use theory of meaning and to the minimal theory of truth that is based on such a theory of meaning. I will begin with indexicals, which are typically characterized by a rule-based linguistic meaning.

\section{Indexicals as systematically polysemous expressions}

According to Kaplan, the meaning of an indexical (or a demonstrative) ${ }^{27}$ in its deictic use has two aspects. ${ }^{28}$ On the one hand it has a constant element-something we all learn when we learn the meaning of a word such as ' $\mathrm{I}$ ', the rule that it refers to the speaker of the utterance of which it is a part. Kaplan called this aspect of the meaning of an indexical its character. On the other hand, the propositional contribution of ' $\mathrm{I}$ ' changes when it is uttered by a different person, the content is thus a non-constant function of the context (Kaplan 1989a). The rather uncontroversially accepted lesson to take home from Kaplan is that some words may have meanings that do not determine their contents directly but provide rules that determine the content in the context of utterance. Even though the content may vary across contexts, indexicals are not ambiguous according to this analysis as each is connected with just one content-

\footnotetext{
27 In what follows I will use the term 'indexical' in such a way as to include demonstratives.

28 Kaplan was obviously not the first to distinguish the two aspects of meaning of an indexical expression. Important authors to mention here are at least Husserl (1901), Burks (1949) and Bar-Hillel (1954). Thanks to an anonymous referee for making me be more precise in this respect. For a more substantive account of the history of research on indexicals see my Kijania-Placek (2012a).
} 
generating rule. ${ }^{29}$ This view on meaning should be acceptable to Horwich, who claims that "we might well deny that meaning determines reference. We might suppose, on the contrary, that the referent of a term is fixed in part by the context in which it occurs." (Horwich 2001, p. 154) He thus seems to believe that deictic uses of indexicals fit comfortably with the use theory of meaning and the minimal theory of truth.

But deictic uses of an indexical, such as "he", are not the only uses of this word considered as a syntactic word-type. In English we can distinguish at least five types of the uses of "he":

I. DEICTIC uses:- based on Kaplanian characters (Kaplan 1989a)

(7) $\mathrm{He}_{\text {[pointing at John Paul II] }}$ is speaking bad Italian.

II. ANAPHORIC uses-based on the rule of anaphora

(8) If John Paul II does not practice his Italian, he will always have a Polish accent.

III. BOUND uses—-based on the rule of binding

(9) If somebody does not practice his Italian, he will always have an accent.

IV. DEFERRED uses-based on the rule of deferred reference (Nunberg 1993, see below)

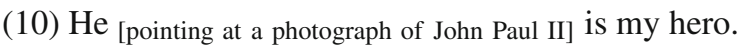

V. DESCRIPTIVE uses-based on the rule of descriptive anaphora (Kijania-Placek 2012a, b, 2015, 2016a; see below)

(11) He is usually an Italian, but this time they thought it wise to elect a Pole.

[uttered by someone gesturing towards JP II as he delivers a speech with a Polish accent shortly after his election.]

In deferred use an indexical refers to an object not present in the immediate context of utterance (called the deferred referent) by way of a different object (called an index), which is present in the context and is related in a contextually salient way to the referent (e.g. reference to an author by way of pointing to his book). Such uses were first distinguished by Nunberg (1978, 1979, 1993). Descriptive uses of indexicals, on the other hand, are uses where indexical utterances express general propositions concerning, for example, all popes (see Nunberg 1993, 2004; Recanati 1993, 2005; Bezuidenhout 1997; Powell 1998, 2010; Elbourne 2005, 2008; Hunter 2010; Stokke 2010; Galery 2008; Kijania-Placek 2012a,b, 2014, 2015, 2016a,b). The important difference between deferred and descriptive uses of indexicals is that in the former the proposition expressed by the utterance is still singular, it is just not about the object

29 At some point Horwich claims that "I am hungry" is multiply ambiguous "designating a separate expression-type for each of the limitless number of different propositions it may be used to express (depending on the speaker and time of utterance)." (1990/1998, p. 100) I see no way of extracting distinct patterns of use for those multiple uses of this sentence, as due to the contribution of time each may occur only once. I will ignore this declaration, as in other places Horwich claims that he is after a meaning of "I" that is common to all its utterances, including those of its translation to different languages (compare 2005, p. 28, quoted in Sect. 1 above). 
demonstrated - the photograph, in the case of (10)_-but about the object related to the photograph by the relation of 'being depicted in the photograph', while in descriptive uses a general proposition is expressed. ${ }^{30}$

Descriptive anaphora is an interpretive mechanism I have postulated for the analysis of the descriptive uses of indexicals in (Kijania-Placek 2010, 2012a, b). In the mechanism of descriptive anaphora, the antecedent of the anaphora stems from the extra-linguistic context: it is an object identified through the linguistic meanings of a pronoun (in the case of pure indexicals) or by demonstration (for demonstratives). ${ }^{31}$ In a communication context, those objects serve as a means of expressing content and, as such, they acquire semantic properties. ${ }^{32}$ The antecedent is used as a pointer to a property corresponding to it in a contextually salient manner and that property contributes to the general proposition expressed. ${ }^{33}$ The context must be very specific in order to supply just one such property, which explains why there are not many convincing examples of the felicitous use of descriptive indexicals. Typically, descriptive anaphora is triggered at the level of linguistic meaning by the use of quantifying words such as "usually" or "always", whose linguistic meanings require a range of objects to quantify over and thus clash with the singularity of the default referential reading of indexicals (or proper names, as will be exemplified in the next section) in their default interpretations. ${ }^{34}$ Those quantifiers need not be overt. As a result, the expression's basic referential function is suppressed. The structure of the general proposition is determined by the binary quantifier, usually the very quantifier that triggered the mechanism of descriptive anaphora in the first place. The anaphora is descriptive in the sense that the antecedent does not provide a referent for the pronoun. It gives a property which is not a referent - the property retrieved from the context serves as a context set that limits the domain of the quantification of the quantifier (see Kijania-Placek 2012a, 2015, 2016a). ${ }^{35}$ The proposed analysis, applied

30 It is an oversimplification to simply talk about singular and general propositions here, as general propositions from the point of view of a descriptively used indexical may contain other indexicals which are used deicticly. Thus, it would be more appropriate to talk about propositions singular or general with respect to specific words. Compare Mackie's notion of propositions "singular with respect to an object" (McKay and Nelson 2014). Having mentioned this problem, I will continue to use the simplified distinction, hoping that doing so should not cause confusion.

31 Compare Kijania-Placek (2012a, 2015). Descriptive anaphora may be extended to the analysis of descriptive uses of proper names (see next section) by postulating that for proper names the extra-linguistic antecedent is the object identified by the social convention concerning the name that is active in the context of an utterance.

32 Compare Frege's treatment of objects as a means of expressing content; e.g. Frege (1892, 1897, 1918), Künne (1992), Poller (2008), Kripke (2008) and Kijania-Placek (2012a).

33 I call the interpretive mechanism "descriptive anaphora" due to the fact that the pronoun when used descriptively is semantically dependent for its interpretation on other elements of - this time extralinguistic_context and acquires their semantic properties; the pronoun is semantically parasitic on other elements of discourse. This view of anaphora is indirectly based on von Fintel (2004) and Roberts (2010).

34 Whether there is a clash is, however, a pragmatic matter, as it depends on the domain of quantification of the quantifier, which for most adverbs of quantification is not given as part of the semantics of the word. Compare Lewis (1975) and Kijania-Placek (2012a, 2016a).

35 The concept of deferred reference is sometimes used inclusively for both cases when a contribution of the indexical is singular and when it is general. On such an inclusive interpretation of deferred reference, descriptive anaphora may be considered an elucidation of the general reading of deferred reference. I have 
to (11), works as follows. In this example the linguistic meaning of 'he' requires reference to one particular person but 'usually' is a quantifier that here quantifies over a set of people. This tension triggers a search for an alternative interpretation via descriptive anaphora, with John Paul II as the demonstrated antecedent. John Paul II is not the semantic value for 'he' as no antecedent is ever a value for the anaphora - it gives the value. The salient property of John Paul II-'being a pope' —is the semantic value of 'he'. 'usually' is a binary quantifier-USUALLY $x(\varphi(\mathrm{x}), \psi(\mathrm{x}))$ analyzed according to the generalized quantifiers theory (e.g. Barwise and Cooper 1981 or Peters and Westerståhl 2006). The structure of the proposition is thus as follows: ${ }^{36}$

$$
\text { USUALLYx (POPE(x), ITALIAN(x)), }
$$

and the quantifier USUALLY has the truth conditions of the majority quantifier:

$$
\mathrm{M}^{\mathrm{gi}} \models \operatorname{USUALLY}_{\mathrm{X}}(\varphi(\mathrm{x}), \psi(\mathrm{x})) \quad \text { iff }\left|\varphi^{\mathrm{Mgi}} \cap \psi^{\mathrm{Mgi}}\right| \geq\left|\varphi^{\mathrm{Mgi}} \backslash \psi^{\mathrm{Mgi}}\right|
$$

Such an analysis gives the intuitive reading for (11): 'Most popes are Italian'. In general, the structure of the interpretation can be given by the following schema:

$$
\text { IND is } \mathrm{Q} \psi \Rightarrow \mathrm{Qx}(\varphi(\mathrm{x}), \psi(\mathrm{x}))
$$

where IND is an indexical, $\mathrm{Q}$ is a quantifier, $\varphi$ is the property corresponding to the object which is the antecedent of IND and $\Rightarrow$ should be read as 'expresses the proposition' (compare Kijania-Placek 2012a, 2016a).

This analysis of descriptive uses of indexicals presupposes at least a partial dependence between different kinds of uses of these expressions. ${ }^{37}$ The mechanism of descriptive anaphora is triggered by the unavailability of other uses of indexicals and as such is dependent on them. The interpretation of (11) is triggered by the semantic inconsistency between the generality of the majority quantifier ("usually") and the singularity of other potentially available referential interpretations of the pronoun, be it deictic, (classically) anaphoric or deferred. Thus for the descriptive interpretation to succeed, the general semantic features of the remaining interpretations must be taken into account even though the other potential contents may not be computable. In a

\footnotetext{
Footnote 35 continued

supported the need for drawing the distinction between deferred reference and descriptive interpretation more extensively in Kijania-Placek (2012a).

36 I use the SMALLCAPS font style for formal counterparts of natural language quantifiers and predicates. $\mathrm{M}$ is a model, $\mathrm{g}$ is an assignment of objects from the domain of the model to individual variables, $\mathrm{i}$ is a context, $\models$ is a satisfaction relation obtaining between a sentence (or an open formula) and a model and context, under an assignment; $\varphi$ and $\psi$ are open formulas, $|\mathrm{A}|$ signifies the cardinality of the set $\mathrm{A}$, and $\varphi^{\mathrm{Mgi}}$ is the interpretation of formula $\varphi$ in model $\mathrm{M}$ and context $\mathrm{i}$ under assignment $\mathrm{g}$.

37 I have elaborated upon the nature of this dependence in Kijania-Placek (2012a, 2015).
} 
sense all the possible interpretive mechanisms are thus activated in the interpretation of a descriptively used indexical.

Other uses of indexicals are not dependent on descriptive uses in a similar way but they are variously interconnected, which is shown by the fact that uniform accounts of either deictic, anaphoric and bound uses (Recanati 2005) or deictic and deferred uses (Nunberg 1993) have been attempted. Even if those attempts may not be considered successful as general theories of indexicals, they point to important interrelations between patterns of use of the respective kinds of use. With respect to deictic, anaphoric and bound types of uses of indexicals Levinson pointed out that "the fact that in language after language all three functions can be performed by the same pronominal expressions suggests that their semantic character simply encompasses all three." (Levinson 2000, p. 270) I think that this claim can be extended to all five functions. The generalized conception of polysemy introduced above allows for the treatment of indexicals as systematically polysemous words and is thus an attempt at such a semantic character that encompasses all of them. In the next paragraph I will point to the specific features of indexicals that are characteristic of systematic polysemy.

The cross-linguistic uniformity of indexicals is well attested, especially for deictic, bound and anaphoric uses. Levinson even goes to the point of formulating the hypothesis that "any language with deictic pronouns will allow these to be used both anaphorically and as variables." (Levinson 2000, p. 409) However, deferred and descriptive uses are sustainable across different languages as well, at least those examples that are based on highly salient relations, such as the authorship of books or on important social functions (pope, queen, president or prime minister). All five types of uses of indexicals are learned as a package and the slightly higher level of difficulty in the comprehensibility of descriptive uses stems from the non-presumptive character of this type of interpretation (compare Kijania-Placek 2016a). The productivity of deictic, anaphoric and bound uses is self-evident and stems from their rule-based character, while the relation between photographs and people depicted in photographs testifies to the high level of productivity of deferred uses. More scene setting is required to establish the productivity of descriptive uses of indexicals but the following example may serve as analogous to (11). Let us consider an American watching Barack Obama's inauguration as president in 2009, who, prompted by the surprised gaze of a foreigner, utters:

(12) He is usually white,

expressing a general proposition:

(12a) US Presidents are usually white.

The above mentioned features of the different uses of indexicals support the treatment of indexicals as rule-based systematically polysemous words but they do not necessarily pose a very serious challenge for Horwich's theory. That is because there seem to be no clear examples of inferential or anaphoric relations across the various uses, which in principle leaves open the possibility of the separation of the types of uses by use patterns. ${ }^{38}$ As I will try to show in the next section, the situation is more

\footnotetext{
38 With regards to anaphoric and quantificational uses of pronouns, Horwich wrote that " $[\mathrm{t}]$ he fact that pronouns have two non-unifiable uses makes the best theory of them regrettably disjointed." (Horwich 2010b,
} 
serious with proper names as they exhibit the full range of features characteristic for systematic polysemy.

\section{Proper names as systematically polysemous expressions}

Until quite recently, proper names were considered mainly or exclusively as devices of singular reference (Mill 1843; Frege 1892; Russell 1911; Kripke 1972; Donnellan 1970). Considered as word-types, however, they also exhibit other kinds of uses. In his influential paper (1973) Burge pointed out that, apart from the usual kind of examples such as:

(13) Alfred studies in Princeton.

[...] [P]roper names take the plural:

(14) There are relatively few Alfreds in Princeton.

They also take indefinite and definite articles:

(15) An Alfred Russell joined the club today.

(16) The Alfred who joined the club today was a baboon.

And quantifiers:

(17) Some Alfreds are crazy; some are sane. (Burge 1973, p. 429; numerals added for future reference)

Burge claims that although "[p]roper names are usually used in singular and unmodified form [...] there is nothing ungrammatical about the above sentences." Burge and his followers (Segal 1996; Geurts 1997; Bach 2002; Elbourne 2005; Matushansky 2006, 2008; Katz 2001; Fara 2011a, b, 2015a, b, c) developed a theory called predicativism. According to predicativists "names are predicates in all of their occurrences" (Fara 2015a, p. 60) and by that they mean "multiply applicable predicates that are true of just those things that are bearers of the name" (Fara 2015b, p. 251). ${ }^{39}$ This conception squares seamlessly with the plural and quantified uses of proper names, as well as using such names with either definite or indefinite articles, but has been challenged by indicating uses of proper names that are not true just of the things that are bearers of a particular name. The following counterexamples have been provided, extending the repertoire of rarely considered types of uses of proper names supplied by Burge:

Family Examples: (Böer 1975)

(18) Joe Romanov (my barber) is not a Romanov;

Footnote 38 continued

p. 30) But even if such disjointed use patterns would be possible to establish for these two kinds of uses of indexicals, it is doubtful if it would be possible for deferred and descriptive uses, as those are systematically related to deictic uses of those expressions.

39 The singular uses in the argument position, appearing as bare singulars — the former "normal" uses-are explained by a stipulation that they constitute the predicative component of a denuded definite descriptionin Fara's and Matushansky's version of predicativism—or the denuded determiner "that"-in Burge's version. 
(19) Waldo Cox (my gardener) is a Romanov (an exciting fact revealed by recent historical investigations).

Costume (Representational) Examples: (Jeshion 2015)

(20) Two Obamas came to the Halloween party.

Resemblance Examples: (Jeshion 2015)

(21) Two little Lenas just arrived.

Artwork (Producer) Examples:

(22) He gave me a Picasso for my birthday.

Machiavelli Examples: (Fara 2015b)

(23) Dick is a real Machiavelli.

The idea is that "Romanov", as used in (18) and (19), does not fall under the predicativist rule, according to which "Romanov" is a predicate that is true of a thing if and only if it is called Romanov, because other properties are decisive as far as belonging to the Romanov dynasty is concerned. Yet, "Romanov" is a proper name and so should be analysable according to the predicativist rule. Analogously, for somebody to count as Obama at a Halloween party or for a painting to count as a Picasso, the respective objects do not have to be bearers of the names.

Referentialists, such as Jeshion, offer arguments for treating only singular uses of proper names in argument position as the real uses of proper names and propose to rely on pragmatic mechanisms for the explanation of other uses. Both theories admit, however, that some uses of proper names considered as syntactic type-Machiavelli examples for referentialists (Jeshion 2015, p. 369), Family examples for predicativists (Fara 2015c, pp. 4, 16) - are explicitly excluded from their considerations, and the decision is justified on semantic grounds. ${ }^{40}$ Such decisions are, however, unacceptable from the point of view of the Horwich version of the use theory of meaning, which cannot be based on semantic concepts and which types words by their "shapes or sounds". On such principles we must just treat as a fact that all the mentioned types of uses are uses of one word, unless it is an example of homonymy, as in the case of "bank". Outside of the camps of the referentialists and predicativists, at least some of these uses (Artwork examples) are typically considered examples of polysemy and in the remainder of this section I will argue for a polysemous treatment of proper names by examining to what extent they exhibit the features of systematic polysemy. ${ }^{41}$

I hope to be able to show that the type of polysemy that is operative in the case of proper names is precisely the rule-based systematic polysemy introduced above. We thus do not expect a set of stable senses determining concrete contents for a proper

\footnotetext{
40 Additionally, neither referentialists nor predicativists account for anaphoric or bound uses of proper names, see below.

41 A polysemous theory of proper names has been proposed by Leckie (2013), but it concerned just individual (she calls them "referential", see footnote 42 below) and predicative uses of proper names. According to Leckie "“Frieda" is ambiguous between the woman and the name "Frieda"' (Leckie 2013, p. 1153). She mentions other uses of names only in passing and does not treat them on a par with predicative and individual uses.
} 
name but a set of rules that generate contents in contexts. Basing the linguistic meaning of a name on a set of rules will allow for an explanation of both the productivity as well as of the systematicity of uses of proper names. Some of the uses of names grouped separately above (Representation Examples and Costume Examples) will turn out to be based on the same mechanism.

\subsection{Typology of uses of proper names}

I propose a treatment of proper names as systematically polysemous words whose linguistic meaning are comprised of the following kinds of uses and the respective mechanisms (abstract content generating rules) underlying those uses:

I. INDIVIDUAL uses-based on the rule of the semantics of direct reference for proper names (see for example Recanati 1993) ${ }^{42}$

(24) Picasso was incredibly prolific. (Jeshion 2015) and (13)

II. PREDICATIVE uses-based on the metasemantic rule of predicative analyses (BBCC condition of Fara 2015a, b, c; Matushansky 2008)

(25) I have come across two Gareth Evans' and two Ken Taylors my readings. and (14)-(17)

III. ANAPHORIC uses—-based on the rule of anaphora

(26) If John insists on calling his next son Gerontius, then his wife will be annoyed and Gerontius will get made fun of because of his name. (Elbourne 2005)

IV. BOUND uses-based on the rule of bounding 43

(27) Every woman who has a husband called John and a lover called Gerontius takes only Gerontius to the Rare Names Convention. (Elbourne 2005)

V. DEFERRED uses-based on the rule of deferred reference (Nunberg 1993, see section 3 above) extended to proper names

(28) France plays Germany tonight. and (32) below

VI. DESCRIPTIVE uses — based on the rule of descriptive anaphora (Kijania-Placek 2012a, 2015, 2016a,b)

(29) If Mary had been a boy then yes, I do believe England would have remained a Catholic country. (Saebo 2015)

and

Family Examples: (18), (19)

Costume (Representational) Examples: (20)

Resemblance Examples: (21)

Artwork (Producer) Examples: (22)

42 Leckie (2013) uses the term "referential" for what I call here "individual" uses of proper names. Her terminology is, however, misleading, as, for example, deferred uses are referential in the semantic sense of contributing their referents to the proposition expressed as well.

43 It is debatable if anaphoric and bound uses are based on separate mechanisms or can be reduced, but I will leave this issue out of my considerations in this paper, as it is unimportant for the main argument, which relies on the multiplicity of mechanisms but not on their exact number. 
Machiavelli Examples: (23) and

(30) Who is the next Einstein? (Jeshion 2015)

Contrary to Nunberg's explicit claims (Nunberg 1992, p. 298), I believe that proper names are susceptible to deferred interpretation and that this interpretation is useful in the analysis of examples such as (28). The relation between index and referent of Nunberg (1993) in the case of proper names is exercised by a salient relation that points from the default referent of a name as used in a context (the index) to the object (the deferred referent) that is thus related to the index. In the case of (28) the deferred referents would be the soccer teams of France and Germany (for example) that are salient in the context.

For deferred reference to work, however, the relation must be functional. ${ }^{44}$ Examples relying on nonfunctional relations, such as Costume, Resemblance, Machiavelli or Artwork examples are better analyzed by descriptive anaphora, because they do not provide individual objects as values but sets of objects: the relation of being dressed as Obama obtains between Barack Obama and not just one but potentially many people. That is why deferred reference cannot be treated as a uniform mechanism explaining all non-referential uses, contrary to the suggestions of Jeshion (2015).

Applied to Costume Examples, descriptive anaphora would work in the following way:

(20) Two Obamas came to the Halloween party.

"Two" is a quantifier that requires a range of objects to quantify over, and because "Obama" in its standard interpretation provides just one object-Barrack Obamathere is a tension in this sentence which triggers the search for an alternative interpretation. According to the descriptive anaphora interpretation, Barrack Obamathe person, not the name-is the extralinguistic antecedent that points in the context of a costume party to a property of being a person dressed as Barack Obama. This property functions as the context set that limits the domain of the quantification of the

\footnotetext{
44 As an anonymous referee rightly pointed out, the functional character of the relation is a contextual matter and depends on the salience of particular objects and intentions of the speakers. This is clearly visible in the case of (28), where deferred reference relies on the relation of France to its salient team even though there are many teams that are related to France. The reliance on the intentional element would not work for descriptive uses of names, however, contrary to the suggestion of the referee. It is true that for descriptive anaphora to work a salient relation must obtain between an object (the descriptive antecedent) and a property related to it in a contextually salient manner. However, that property is not a referent of the term in the sense that it is not a propositional constituent, which is an object of predication, but it contributes to the proposition by constraining the domain of quantification of the binary quantifier (or by forming a predicate, in Machiavelli examples). It does contribute to the proposition but not as an object of predication - a referent - but rather as a predicate, a distributive property. In general, deferred reference to properties considered as abstract objects is possible and in fact it is the only available way of demonstrative reference to such objects (compare Quine 1968 and Nunberg 1978). If we point to a token of the letter $\alpha$ and say "This begins the Greek alphabet", we refer to an abstract object in a deferred way. In the same way, when we point to a picture of a square and say "This is relatively easy to define", we refer to the property of squareness and attribute the property of being relatively easy to define to it. The deferred referent- the property-is an argument for the property that is attributed to it. In contrast, for the analyses of, for example, quantified uses of names, such as (20), we need a propositional contribution that is a distributive property and as such would yield several objects to quantify over, instead of a property which is an abstract object referred to. Compare also note 35 above.
} 
quantifier "two", giving the following general proposition as an interpretation of this utterance:

TWO $_{\mathrm{x}}($ PERSON-DRESSED-AS-OBAMA(x), CAME-TO-THE-HALLOWEEN-PARTY(x)), and the quantifier Two has the following truth conditions:

$$
\mathrm{M}^{\mathrm{gi}} \models \mathrm{TWO}_{\mathrm{x}}(\varphi(\mathrm{x}), \psi(\mathrm{x})) \text { iff } \quad \varphi^{\mathrm{Mgi}} \subseteq \psi^{\mathrm{Mgi}} \text { and }\left|\varphi^{\mathrm{Mgi}}\right|=2
$$

- Two people dressed as Obama came to the Halloween party.

Due to the requirements of salience that are operative in deferred and descriptive uses not all names will have exhibited all six kinds of use but that is just an accidental matter and does not preclude a use of a certain kind of a given name, providing context cooperates.

\subsection{The polysemous character of the meaning of proper names}

The following phenomena seem to support the hypothesis that proper names exhibit systematically polysemous meanings:

(a) Cross-linguistic sustainability of the polysemous meaning of proper names Examples of uses of proper names which are based on the mechanism of deferred reference and rely on alterations between, for example, authors and their works provide robust data supporting the sustainability of polysemous meanings in translation. Thus in (31):

(31) I met Kripke last week vs. I haven't read Kripke in a while.

the name "Kripke" functions in exactly the same way as the translation of (31) into Polish:

(31a) W ubiegłym tygodniu spotkałam Kripkego. vs. Od jakiegoś czasu nie czytałam Kripkego.

The same is true of German and many other languages. But cross-linguistic sustainability for rule-based systematic polysemy should really be understood in the formal sense of the availability of the seven mechanisms of interpretation for a proper name with the possibility that for different languages, for example, alternative specific relations will be available as the basis for deferred reference. The prediction of the proposed conception concerning descriptive or deferred uses will thus only be that proper names exhibit these kind of uses and not that those uses will depend on the same specific relations systematically available in respective languages. Especially in descriptive uses, the salience of different properties may be culturally and socially dependent, ${ }^{45}$ and thus different properties may be available as the basis for descriptive anaphora, not just in different contexts but also in different languages.

(b) Combined knowledge of polysemous meanings

45 Compare the salience of the role of a bishop in Catholic and Muslim countries. 
This feature of proper names is closely connected with cross-linguistic sustainability and should be understood in a similarly abstract way. Competent users of language must implicitly know the semantics of proper names, i.e. the semantic mechanisms that underlie their usage. Furthermore, once somebody has a particular proper name in his linguistic repertoire as an individual name (knows whose name it is), he will be able to use it anaphorically, predicatively or in a deferred way, relying for example on the salient relation between countries and their governments for the name "Ecuador":

(32) I have been to Ecuador last year. vs. Ecuador voted against this resolution last week.

Bound uses do not even require knowledge other than the fact that a particular word is a proper name to be understood cross-linguistically. Family uses depend on factual knowledge, while descriptive uses depend on the knowledge of the conventionalized or stereotypical, or at least highly salient, features of a particular person. Thus somebody who does not know who Martha Stewart is will be unable to use that name descriptively or understand an utterance containing such a use. ${ }^{46}$ Once such knowledge about stereotypes is available, however, the mechanism of descriptive anaphora is implicitly available for everybody who knows the name.

(c) Productivity and creativity

Productivity and creativity follows immediately from the fact that the respective uses of proper names are not specified by stable contents but by underlying rules that may give different contents in different contexts. Since the variability of context is operative in all kinds of uses apart from bound uses, novelty should be expected, especially from the deferred and descriptive uses of proper names. In (2006) Gooden listed 425 attested adjectival forms of names, mostly derived from the names of people. Some of them, like "Machiavelli", are used both as adjectives (Machiavellian) and in an unchanged form ((23) above), with the same meaning. Adjectival forms are more frequent but it seems that all unchanged forms, even if never used in such a way, would be immediately comprehensible. Whatever meaning has been communicated by "Mozartian" in "Simultaneously suggesting happiness, regret, and a keen awareness of the hurt that lies at the heart of love, Dench achieves a Mozartian richness of feeling" (Daily Telegraph, quoted after Gooden 2006, p. 130), could be communicated as well by ending this phrase with "Dench is a Mozart as far as the richness of feeling is concerned" instead.

(d) Anaphoric relations across polysemous meanings

Felicitous anaphoric relations across polysemous meanings of proper names are pervasive with such openly polysemous words as names of newspapers:

(33) I do not usually read the Guardian, but I bought it today.

(e) Inferential relations across polysemous meanings

46 Such as the following: "The next house belongs to a woman known to Holly and Merge as a 'friggin bitch,' who turns out to be Martha Stewart or at least a very dedicated acolyte thereof." Barbara Ehrenreich, Nickel and Dimed. On (Not) Getting By in America. A Metropolitan/ Oel Book, Henry Holt and Company, New York, 2002, p. 97. 
Inferential relations between individual and predicative uses of names in so-called mixed arguments were treated by predicativists as an important argument for inclusion of predicative uses in the analysis of the meaning of proper names. Thus, we can make the following inference:

(34) Tom Smith joined our class today. So there are three Toms now.

In (34) the second proposition follows from the first (and an enthymematic assumption that two Toms were in the class before). That fact is difficult to account for if we do not include plural uses of names in the semantics of these expressions (compare Leckie 2013). Other examples include:

(35) Frieda is painting. So, at least one Frieda is painting. (Leckie 2013)

or

(36) No Friedas are Iranian. So, Frieda isn't Iranian. (Leckie 2013)

The last two examples show the symmetrical inferential dependence of individual and predicative uses of names. When we consider that inferential patterns inform Horwich as to the meaning of a word (see note 5 above), the above cases seem to exclude the possibility of the separation of the predicative and individual uses of names into two homonyms. For the inference in (35) to be acceptable, the name in the premise must be used individually and predicatively at the same time, which shows that these uses may not always be separated by context, excluding the relativization to context deployed by Horwich for indexicals as a means of retaining the acceptability of the equivalence schema. Additionally, for any inference to make sense, the meaning of the terms in the premises and in the conclusion must be identical. It follows that for the validity of the inference in (35) "Frieda" in the premise must have both its individual and its predicative sense and that this double meaning must be retained in the conclusion.

This phenomenon of the permeability of meanings is characteristic of systematic polysemy, as I have pointed out in section 2.2. and is not problematic for theories, which separate meaning from propositional contribution (content) in a Kaplanian way. Yet it is problematic for Horwich, who on the one hand wants to define propositions by the equivalence of meaning (1990/1998, p. 134), and on the other requires the reduction of meaning to basic patterns of use. Since basic patterns of use must account for "the usage of all the complexes into which they [the words] enter" (2005, p. 218), including (35) for "Frieda", the double meaning will spread from (35) into all propositional contributions of this word. Thus the propositional contribution of "Frieda" will have to retain both its predicative and its referential character across all its uses. Even if we were to find a way of making sense of what such a stance amounts to, this contradicts Horwich's claim that the propositional constituent corresponding to an individually used name (which is a de re use) is simply the referent. ${ }^{47}$

Additionally, due to the non-compositional character of the equivalence schema (Horwich 1990/1998, p. 11), it applies mechanically to the one-sentence version of (35):

47 "As for the identity of a de re propositional constituent, it is simply the referent of the term used to articulate it." (Horwich 1998, p. 85) 
(35a) Since Frieda is painting, at least one Frieda is painting.

yielding the following equivalence instance:

(35b) $<<$ Since Frieda is painting, at least one Frieda is painting $>$ is true iff since Frieda is painting, at least one Frieda is painting. $>$

Horwich requires that for the equivalence instance to be acceptable, a word must have the same propositional contribution on both sides of the equivalence. But in this case "Frieda" has four occurrences and they all should comprise both the referential and predicative aspects of the word, due to the acceptability of the inference depicted in (35) and (35a). Yet, the proposition expressed by the right-hand side of the equivalence is compositionally dependent on two propositions: that Frieda is painting and that at least one Frieda is painting and should just be, according to Horwich, a product of them being combined by the sentential operator "since". Because the contribution of "Frieda" to the first proposition seems to be a person (presumably Frieda Kahlo) while in the second it is the property of being called "Frieda", their contributions are not identical and, more importantly, none is identical to the meaning delivered by UTM that comprises both the referential and predicative aspects of the use of this name. It seems that the desiderata of UTM accounting for inference schemes and the requirements of the theory of truth that call for propositional constituents pull in opposite directions: to make sense of the inference we must rely on both kinds of meanings, while to obtain propositions we must choose between them. What UTM delivers is thus linguistic meaning, which accounts adequately for inference relations but is not by itself suitable as a propositional constituent to figure in particular instances of the equivalence schema. And simple relativization to context that in the case of deictic uses of indexicals was supposed to guarantee the uniform interpretation of occurrences of the same word on both sides of the equivalence schema would give inadequate results for (35b). ${ }^{48}$

Even if no inferential relations are established across other types of uses of proper names, the above cases create a serious obstacle to the prospect of finding the set of basic sentences for each name that would account for all its uses. Additionally, descriptive uses are dependent on deictic and other uses in the sense that descriptive interpretation is triggered by the unavailability of other potential uses. Such an unavailability must be implicitly registered by the hearer for the descriptive interpretation to be considered. The activation of descriptive meaning thus requires the simultaneous activation of the other meanings of a proper name. ${ }^{49}$

\footnotetext{
48 The straightforward numbering of occurrences of words in a sentence - which might come to mind as a natural simple solution to multiple occurrence of a word in a sentence - would fail for languages with different word order.

49 One possible objection to the presented account of proper names considered as a challenge for Horwich's theory of truth and meaning is to draw the attention of the reader to Horwich's often repeated claim that "UTM merely aims to specify how the literal semantic meanings of words are constituted, and not their pragmatic meanings" (Horwich 2005, p. 41; compare also p. 28 and 199) and to claim that only the typical individual uses of proper names are literal. But Horwich did not provide any grounds for the distinction between the literal and non-literal uses of words. The examples he offered ("“She's a genius" does not mean either "She's incompetent" or "Let's give her the job""; 2005, p. 28) are examples of implicatures and are quite dissimilar to the cases of, for example, predicative uses of names. There is little hope for finding
} 


\section{Conclusion}

In the previous section I have argued for the treatment of proper names as systematically polysemous expressions. Let the author be the first to admit that this case requires further clarification and argumentation. ${ }^{50} \mathrm{I}$ shall not attempt it here, however, as my argument against Horwich relies not so much on the partly terminological issue of polysemy, as on the particular systematic features I hope to have shown proper names possess when regarded as word-types in the sense of Horwich. They exhibit at least six types of uses and each type is underlined by a different context-dependent content generating mechanism. Each proper name may thus be used to express a virtually unlimited number of contents but, due to the systematic nature of the underlying mechanisms, the contents are cross-linguistically uniform and predictive. The important point to note, however, is the fact that anaphoric relations across different contents are felicitous and that inferential relations depending on different contents of the same proper name are accepted. In some cases the interpretation even requires simultaneous access to more than one content. This gives a picture of a highly interrelated structure of contents for a single proper name. Yet, as Horwich notes, for the truth defining equivalences to hold, proper names on both sides of the equivalence sign must be "interpreted" in the same way. If sameness of interpretation means identity of content, the validity of the basic equivalences is inconsistent at least with the

Footnote 49 continued

non-semantic grounds for treating predicative uses of names as non-literal, given their common acceptance and systematic inferential interrelation with individual uses of those expressions.

Yet both predicativists (Fara 2015a) and referentialists (Jeshion 2012) tend to treat Machiavelli type of descriptive uses as metaphorical and this case requires an extended argument for which there is no place in this paper. In a nutshell, metaphorical accounts rely on operations on linguistic meaning and it is highly debatable if proper names have linguistic meaning. Even if we assume that they have, the meaning would either reduce to the being called condition (predicativists, Recanati 1993) or be an identifying descriptive condition (for classical descriptivists). It seems, however, that no obvious operation on "being a person called Jim Morrison", without reference to the relevant bearer of that name, would provide the properties that are needed for conveying the meaning expressed by "When I was younger I wanted to be Jim Morrison" (Michael Cunningham, A Home at the End of the World, Penguin Books) and, in general, no relevant relation seems to exist between the property of being called by a name and any properties that are relevant in the analysis of Machiavelli examples. The situation seems to be better on descriptivist grounds, but here the definite description that forms the meaning of a name is neither necessary nor sufficient for the derived meaning. Firstly, the intended meaning of "Einstein" in "He is an Einstein" is "being a genius" and that may be not related to the definite description that would be the identifying property that forms the descriptivist meaning of "Einstein". The insufficiency follows from the fact that if the derived meaning were a result of a meaning change of the description, it should be possible in principle for each proper name. But if John Smith is a name of my non-conspicuous neighbor, I cannot use his name in this way. The reason stems from the fact that Machiavelli uses require the salience of some characteristics of a particular person in a social context that may have nothing to do with the referent fixing description.

More importantly, however, since descriptivism as a theory of proper names relies on semantic concepts such as the concept of satisfaction, which are explicitly rejected by Horwich in the formation of a theory of meaning, this route would also be closed to him even if it were available as the basis of the metaphorical interpretation of some uses of proper names.

50 As an anonymous referee suggested, the concept of systematic polysemy itself requires more elaboration. As presented, it is taken uncritically from the linguistic literature, mostly of a descriptive character. I shall not attempt a critical examination of the concept in this paper, however, as it is not immediately relevant for the main argument against Horwich, which depends on constitutive and inferential interdependencies of different kinds of uses of proper names. But see notes 20 and 23 above. 
actual comprehensibility of argument schemas involving proper names that must rely on the interplay between two contents in every context. Additionally, since according to the use theory of meaning the individuation of contents must not rely on semantic concepts, it is doubtful if contents which are necessarily interrelated by inference and anaphoric schemas can be distinguished by use patterns which are reducible to such basic uses that "have consequences for the usage of all the complexes into which they enter." (2005, p. 218)

I have concentrated my arguments on the case of proper names due to the relatively little attention their non-individual uses have acquired outside of the predicativists camp. I do not claim to have posed an unsurmountable difficulty for the minimal theories of truth and meaning of Paul Horwich, but rather to have uncovered a challenge for his theory within the confines of the very natural language around which the theory has been designed.

Open Access This article is distributed under the terms of the Creative Commons Attribution 4.0 International License (http://creativecommons.org/licenses/by/4.0/), which permits unrestricted use, distribution, and reproduction in any medium, provided you give appropriate credit to the original author(s) and the source, provide a link to the Creative Commons license, and indicate if changes were made.

\section{References}

Apresjan, J. D. (1973). Regular polysemy. Linguistics, 142, 5-32.

Bach, K. (2002). Giorgione was so-called because of his name. Nous, 36, 73-103.

Bar-Hillel, Y. (1954). Indexical expressions. Mind, 63, 359-379.

Barwise, J., \& Cooper, R. (1981). Generalized quantifiers and natural language. Linguistics and Philosophy, 4, 159-219.

Bezuidenhout, A. (1997). Pragmatics, semantic underdetermination and the referential/attributive distinction. Mind, 106, 375-409.

Blutner, R. (1995). Prototypen und kognitive Semantik. In G. Harras (Ed.), Die Ordnung der Worter (pp. 227-270). Berlin: de Gruyter.

Böer, S. (1975). Proper names as predicates. Philosophical Studies, 27(6), 389-400.

Burge, T. (1973). Reference and proper names. Journal of Philosophy, 70(14), 425-439.

Burks, A. (1949). Icon, index, and symbol. Philosophy and Phenomenological Research, 9, 673-689.

Chomsky, N. (2000). New horizons in the study of language and mind. New York: Cambridge University Press.

Dancy, J. (2004). Ethics without principles. Oxford: Oxford University Press.

Donnellan, K. (1970). Proper names and identifying descriptions. Synthese, 21(3-4), 335-58.

Elbourne, P. (2005). Situations and individuals. Boston: MIT Press.

Elbourne, P. (2008). Demonstratives as individual concepts. Linguistics and Philosophy, 31, 409-466.

Falkum, I. (2011). The semantics and pragmatics of polysemy: A relevance-theoretic account. $\mathrm{Ph} . \mathrm{D}$. Thesis, University College London.

Fara, D. (2011a). You can call me 'stupid',. just don't call me stupid. Analysis, 71, 492-501.

Fara, D. (2011b). Socratizing. American Philosophical Quarterly, 48(3), 229-238.

Fara, D. (2015a). Names are predicates. Philosophical Review, 124(1), 59-117.

Fara, D. (2015b). 'Literal' uses of proper names. In A. Bianchi (Ed.), On reference (pp. 249-277). Oxford: Oxford University Press.

Fara, D. (2015c). 'Romanov' is not always a name. Retrieved July 16, 2016 from https://www.princeton. edu/ dfara/papers/fara-RomanovNotAlwaysName.pdf.

Frege, G. (1884). Die Grundlagen der Arithmetik: eine logisch-mathematische Untersuchung über den Begriff der Zahl. Breslau: W. Koebner. 
Frege, G. (1892). Über Sinn und Bedeutung. Zeitschrift für Philosophie und philosophische Kritik, 100, 25-50.

Frege, G. (1897). Logik. transl. In Posthumous writings (Vol. 1979, pp. 126-151). Chicago: University of Chicago Press.

Frege, G. (1918). Der Gedanke. Eine Logische Untersuchung. Beiträge zur Philosophie des deutschen Idealismus I, 1918-1919, 58-77.

Gale, W., Church, K., Yarowsky, D. (1992). One sense per discourse. In Proceedings of the ARPA Workshop on Speech and Natural Language Processing (pp. 233-237).

Galery, T. (2008). Singular content and deferred uses of indexicals (Vol. 20, pp. 157-201). UCL Working Papers in Linguistics.

Gibbard, A. (2008). Horwich on meaning. Mind, 117, 141-166.

Gooden, P. (2006). Name dropping? A no-nonsense guide to the use of names in everyday language. London: A\&C Black.

Geurts, B. (1997). Good news about the description theory of names. Journal of Semantics, 14, 319-348.

Horwich, P. (1998). Meaning. Oxford: Clarendon.

Horwich, P. (1990/1998). Truth (2nd ed.). Oxford: Blackwell.

Horwich, P. (2001). A defense of minimalism. Synthese, 126, 149-165.

Horwich, P. (2005). Reflections on meaning. Oxford: Clarendon Press.

Horwich, P. (2008a). What's truth got to do with it? Linguistics and Philosophy, 31, 309-322.

Horwich, P. (2008b). A new framework for semantics. Philosophical Perspectives, 22, 233-240.

Horwich, P. (2008c). Ungrounded reason. Journal of Philosophy, 105, 453-471.

Horwich, P. (2010a). What is truth? In Truth-meaning-reality (pp. 1-11).

Horwich, P. (2010b). Varieties of deflationism. In Truth-meaning-reality (pp. 13-34).

Horwich, P. (2010c). A defense of minimalism. In Truth-meaning-reality (pp. 35-56). A revised version of Horwich (2001).

Horwich, P. (2010d). Regularities, rules, meanings, truth conditions, and epistemic norms. In Truth-meaningreality (pp. 113-141).

Hunter, J. (2010). Presuppositional Indexicals. Ph.D. Thesis, The University of Texas at Austin.

Husserl, E. (1901). Logische Untersuchungen: Untersuchungen zur Phänomenologie und Theorie der Erkenntnis (Vol. 2). Halle: Niemeyer.

Jeshion, R. (2012). A rejoinder to Fara's “'Literal' uses of proper names”. Retrieved July 16, 2016 from http://usc.academia.edu/RobinJeshion.

Jeshion, R. (2015). Referentialism and predicativism about proper names. Erkenntnis, 80, 363-404.

Kaplan, D. (1989a). Demonstratives. In J. Almog, J. Perry, \& H. Wettstein (Eds.), Themes from Kaplan (pp. 481-563). Oxford: Oxford University Press.

Kaplan, D. (1989b). Afterthoughts. In J. Almog, J. Perry, \& H. Wettstein (Eds.), Themes from Kaplan (pp. 565-614). Oxford: Oxford University Press.

Katz, J. (2001). The end of Millianism: Multiple bearers, improper names, and compositional meaning. The Journal of Philosophy, 98(3), 137-166.

Kijania-Placek, K. (2010). Descriptive indexicals and the referential/attributive distinction. In M. Pelis (Ed.), Logica yearbook 2009 (pp. 121-130). London: College Publications.

Kijania-Placek, K. (2012a). Pochwała okazjonalności. Analiza deskryptywnych użyć wyrażeń okazjonalnych [Praise of indexicality. An analysis of descriptive uses of indexicals, in Polish]. Warsaw: Semper.

Kijania-Placek, K. (2012b). Deferred reference and descriptive indexicals. Mixed cases. In P. Stalmaszczyk (Ed.), Philosophical and formal approaches to linguistic analysis (pp. 241-261). Frankfurt: Ontos Verlag.

Kijania-Placek, K. (2014). Situation semantics, time and descriptive indexicals. In P. Stalmaszczyk (Ed.), Semantics and beyond. Philosophical and linguistic inquiries (pp. 127-148). Berlin: Walter De Gruyter.

Kijania-Placek, K. (2015). Descriptive indexicals, propositional attitudes and the double role of context. In H. Christiansen, I. Stojanovic, \& G. Papadopoulos (Eds.), Modeling and using context. LNAI 9405 (pp. 287-301). Dordrecht: Springer.

Kijania-Placek, K. (2016a). Descriptive indexicals and epistemic modality. Topoi. doi:10.1007/s11245015-9340-5

Kijania-Placek, K. (2016b) Indexicals and names in proverbs. Studies in Logic, Grammar and Rhetoric (Forth comming). 
Koskela, A., \& Murphy, M. L. (2006). Polysemy and Homonymy. In K. Brown (Ed.), Encyclopedia of Language and Linguistics (2nd ed.).

Kripke, S. (1972). Naming and necessity. In G. Harman \& D. Davidson (Eds.), Semantics of natural language (pp. 253-355). Dordrecht: D. Reidel Publishing Co.

Kripke, S. (2008). Frege's theory of sense and reference: Some exegetical notes. Theoria, 74, 181-218.

Krovetz, R. (1998). More than one sense per discourse. NEC Princeton NJ Labs, Research Memorandum.

Künne, W. (1992). Hybrid proper names. Mind, 101, 721-731.

Leckie, G. (2013). The double life of names. Philosophical Studies, 165, 1139-1160.

Levinson, S. (2000). Presumptive meanings: The theory of generalized conversational implicature. Cambridge, MA: MIT Press.

Lewis, D. (1975). Adverbs of quantification. In E. Keenan (Ed.), Formal semantics of natural language (pp. 3-15). Cambridge: Cambridge University Press.

Lyons, J. (1977). Semantics. Cambridge: Cambridge University Press.

Matushansky, O. (2006). Why rose is the rose: On the use of definite articles in proper names. In O. Bonami, \& P. Cabredo Hofherr (Eds.), Empirical issues in syntax and semantics (Vol. 6, pp. 285-307).

Matushansky, O. (2008). On the linguistic complexity of proper names. Linguistics and Philosophy, 21, 573-627.

McKay, T., \& Nelson, M. (2014). Propositional attitude reports. In Edward N. Zalta (Ed.), The Stanford encyclopedia of philosophy (Spring 2014 Edition). Retreived January 9, 2016 from http://plato.stanford. edu/archives/spr2014/entries/prop-attitude-reports/.

Mill, J. S. (1843). A system of logic. London: Parker.

Nunberg, G. (1978). The pragmatics of reference. Bloomington: Indiana Linguistics Club.

Nunberg, G. (1979). The non-uniqueness of semantic solutions: Polysemy. Linguistics and Philosophy, 3, 143-184.

Nunberg, G. (1992). Two kinds of indexicality (Vol. 40, pp. 283-302). Ohio State University Working Papers in Linguistics.

Nunberg, G. (1993). Indexicality and deixis. Linguistics and Philosophy, 16, 1-43.

Nunberg, G. (1995). Transfers of meaning. Journal of Semantics, 12(2), 109-132.

Nunberg, G. (2004). The pragmatics of deferred interpretation. In L. R. Horn \& G. Ward (Eds.), The handbook of pragmatics (pp. 344-364). Oxford: Blackwell.

Panman, O. (1982). Homonymy and polysemy. Lingua, 58, 105-136.

Perry, J. (2012). Reference and reflexivity (2nd ed.). Stanford: CSLI Publications.

Peters, S., \& Westerståhl, D. (2006). Quantifiers in language and logic. Oxford: Clarendon Press.

Pethö, G. (2001). What is polysemy? A survey of current research and results. In E. Nemeth \& K. Bibok (Eds.), Pragmatics and flexibility of word meaning (pp. 175-224). Amsterdam: Elsevier.

Poller, O (2008). Wyrażenia okazjonalne jako wyrażenia funkcyjne w semantyce Gottloba Fregego [Indexicals as functional expressions in the semantics of Gottlob Frege; in Polish]. Diametros 17, 1-29; published under the name Volha Kukushkina.

Powell, G. (1998). The deferred interpretation of indexicals and proper names (Vol. 10, pp. 1-32). UCL Working Papers in Linguistics.

Powell, G. (2010). Language, thought and reference. Hampshire: Palgrave Macmillan.

Pustejovsky, J. (1995). The generative Lexicon. Cambridge, MA: MIT Press.

Quine, W. V. O. (1968). Ontological relativity. Journal of Philosophy, 65, 185-212.

Recanati, F. (1993). Direct reference: From language to thought. Oxford: Blackwell.

Recanati, F. (2005). Deixis and anaphora. In Z. G. Szabó (Ed.), Semantics versus pragmatics (pp. 286-316). Oxford: Oxford University Press.

Roberts. (2010). Retrievability and incomplete descriptions. Retrieved July 16, 2016 from http://www.ling. ohio-state.edu/ croberts/Retrievability.pdf.

Russell, B. (1911). Knowledge by acquaintance and knowledge by description. In Mysticism and logic. London: Routledge, 1986.

Saebo, K. (2015). Lessons from descriptive indexicals. Mind. doi:10.1093/mind/fzv031.

Segal, G. (1996). Two theories of names. Mind and Language, 16(5), 547-563.

Stokke, A. (2010). Indexicality and presupposition. Explorations beyond truth-conditional information. Ph.D. Thesis, University of St Andrews.

Tarski, A. (1933). Pojecie prawdy w jezykach nauk dedukcyjnych [The concept of truth in deductive sciences; in Polish]. Warsaw: Towarzystwo Naukowe Warszawskie. 
Tarski, A. (1958). Logic, semantics, metamathematics: Papers from 1923 to 1938. Oxford: Oxford University Press.

Taylor, J. R. (1989/2003). Linguistic categorization (3rd ed.). Oxford: Oxford University Press.

von Fintel, K. (2004). A minimal theory of adverbial quantification. In H. Kamp \& B. Partee (Eds.), Context-dependence in the analysis of linguistic meaning (pp. 137-175). Amsterdam: Elsevier. 